\title{
Effect of radiation on the expression of osteoclast marker genes in RAW264.7 cells
}

\author{
BING YANG $^{1}$, HUI ZHOU ${ }^{2}$, XIAO-DONG ZHANG ${ }^{1}$, ZHENG LIU $^{1}$, FEI-YUE FAN ${ }^{1}$ and YUAN-MING SUN ${ }^{1}$ \\ ${ }^{1}$ Tianjin Key Laboratory of Molecular Nuclear Medicine, Institute of Radiation Medicine, \\ Chinese Academy of Medical Sciences and Peking Union Medical College, Tianjin 300192; \\ ${ }^{2}$ School of Pharmacy, Tianjin Medical University, Tianjin 300070, P.R. China
}

Received November 8, 2011; Accepted January 20, 2012

DOI: $10.3892 / \mathrm{mmr} .2012 .765$

\begin{abstract}
Cancer radiation therapy can cause skeletal complications, such as osteopenia and osteoporosis. To understand the mechanism responsible for the skeletal complications, the expression profiles of osteoclast marker genes in RAW264.7 cells were observed. Osteoclast formation was established by RAW264.7 cells that were treated with the receptor activator of nuclear factor (NF)- $\mathrm{B}$ ligand (RANKL) and detected using immunochemistry and morphological observations. Quantitative real-time polymerase chain reaction was used to assess the expression of a panel of osteoclast markers, including the receptor activator of NF- $\mathrm{KB}$ (RANK), tartrateresistant acid phosphatase (TRAP), integrin $\beta 3$ and the calcitonin receptor (CTR). RANKL-induced osteoclasts were TRAP-positive and multinucleated, and displayed a distinct morphology. RANKL-induced osteoclast precursor cells had increased TRAP and RANK expression and decreased CTR expression compared to the control cells not treated with RANKL. RAW264.7 cells irradiated with 2-Gy $\gamma$-rays had upregulated integrin $\beta 3$ and RANK expression and downregulated CTR expression compared to the control RAW264.7 cells. The effect of radiation on RANKL-induced osteoclast differentiation enhanced the expression of CTR and inhibited the expression of RANK and TRAP. Therefore, radiation damage from 2-Gy $\gamma$-rays can promote the activities of osteoclast precursor cells, but not those of osteoclasts.
\end{abstract}

\section{Introduction}

Previous studies have shown that radiation therapy can cause unavoidable post-radiation impairments, such as osteopenia and osteoporosis. Skeletal complications of radiation therapy have been described in breast, brain and pelvic cancer as well

Correspondence to: Dr Yuan-Ming Sun, Tianjin Key Laboratory of Molecular Nuclear Medicine, Institute of Radiation Medicine, Chinese Academy of Medical Sciences and Peking Union Medical College, Tianjin 300192, P.R. China

E-mail: sym0702-dc@hotmail.com

Key words: RAW264.7 cells, osteoclast, radiation as in leukemia (1-4). Osteoclast precursors have the potential to differentiate into osteoclasts and are hypersensitive to radiation. We hypothesized that irradiated osteoclast precursors are associated with bone loss caused by radiation. To date, little information is available on the effects of irradiated osteoclast precursors on osteoclast dysfunction.

RAW264.7 cells are mouse monocyte/macrophage cells; they are regarded as osteoclast precursors (5) and differentiate into tartrate-resistant acid phosphatase (TRAP)-positive multinuclear osteoclasts following treatment with the nuclear factor (NF)- $\kappa \mathrm{B}$ ligand (RANKL) (6-8).

To investigate the role of irradiated osteoclast precursors in the formation of abnormal osteoclasts, RAW264.7 cells were irradiated and differentiated into osteoclasts in vitro. In the present study, quantitative real-time polymerase chain reaction (QRT-PCR) was used to assess the expression of a panel of osteoclast marker genes.

\section{Materials and methods}

Cell culture. RAW264.7 cells were obtained from the Cell Bank of the Institute of Basic Medicine at the Chinese Academy of Medical Science (Beijing, China) and maintained in Dulbecco's modified Eagle's medium (DMEM; Invitrogen), which was supplemented with $10 \%$ heat-inactivated fetal bovine serum (FBS; Gibco) and $100 \mu \mathrm{g} / \mathrm{ml}$ of penicillin/streptomycin, in a humidified atmosphere of $5 \% \mathrm{CO}_{2}$ at $37^{\circ} \mathrm{C}$, until reaching $80 \%$ confluency. The medium was changed every 3 days.

RAW264.7 cells were divided into 4 groups: Group A, normal RAW264.7 cells used as the control group; group B, RAW264.7 cells cultivated in the presence of $50 \mathrm{ng} / \mathrm{ml}$ of RANKL (PeproTech) for osteoclast formation (9); group C, RAW264.7 cells exposed to 2-Gy $\gamma$-rays to irradiate the osteoclast precursor cells; and group D, RAW264.7 cells treated with both 2-Gy $\gamma$-rays and $50 \mathrm{ng} / \mathrm{ml}$ of RANKL to induce osteoclast formation with radiation damage. All groups were maintained for 7 days. As a radiation source, ${ }^{137} \mathrm{Cs}$ was used.

Assessment of TRAP-positive cells. The TRAP kit was purchased from the Science and Technology Company of the Institute of Hematology at the Chinese Academy of Medical Sciences (Tianjin, China). After the cells were fixed with para- 
Table I. Sequences of primers for quantitative real-time polymerase chain reaction.

\begin{tabular}{|c|c|}
\hline Target & Primers $\left(5^{\prime}-3^{\prime}\right)$ \\
\hline TRAP & $\begin{array}{l}\text { Forward: AGGACGTGTTCTCTGACCG } \\
\text { Reverse: CGCAAACGGTAGTAAGGG }\end{array}$ \\
\hline CTR & $\begin{array}{l}\text { Forward: TAGGAGGTGGAGGATAGC } \\
\text { Reverse: TGACTTGGTGTTGAGGAC }\end{array}$ \\
\hline Integrin $\beta 3$ & $\begin{array}{l}\text { Forward: CCTTCGGATTGGCTTTGG } \\
\text { Reverse: TCATTGAAGCGGGACACC }\end{array}$ \\
\hline RANK & $\begin{array}{l}\text { Forward: GTCTGCAGCTCTTCCATG } \\
\text { Reverse: TCCCTTCCTGTAGTAAACG }\end{array}$ \\
\hline$\beta$-actin & $\begin{array}{l}\text { Forward: GGGTGTGATGGTGGGAATG } \\
\text { Reverse: CTCATTGTAGAAGGTGTGGTGC }\end{array}$ \\
\hline
\end{tabular}

TRAP, tartrate-resistant acid phosphatase; CTR, calcitonin receptor; RANK, receptor activator of nuclear factor- $\kappa \mathrm{B}$.

formaldehyde and incubated with the TRAP solution at $37^{\circ} \mathrm{C}$ for $1 \mathrm{~h}$, the cells were washed in distilled water and counterstained with hematoxylin. Multinucleated TRAP-positive cells were observed using an inverted phase contrast microscope, and their images were captured.

RNA extraction, reverse transcription and QRT-PCR analysis. Total RNA was extracted using the TRIzol reagent (Invitrogen). First-strand cDNA was synthesized using the reverse transcription kit (Takara) with total RNA $(4 \mu \mathrm{g})$. QRT-PCR analyses for TRAP, calcitonin receptor (CTR), integrin $\beta 3$ and receptor activator of NF-kB (RANK) were performed using the ABI Prism 7000 sequence detection system (Applied Biosystems) with Platinum ${ }^{\circledR}$ SYBR-Green qPCR SuperMix-UDG (Invitrogen). The reaction conditions were: $50^{\circ} \mathrm{C}$ for $2 \mathrm{~min}$ and $95^{\circ} \mathrm{C}$ for $10 \mathrm{~min}$, followed by 40 cycles of $95^{\circ} \mathrm{C}$ for $30 \mathrm{sec}$ and $60^{\circ} \mathrm{C}$ for $45 \mathrm{sec}$. The levels of $\beta$-actin mRNA were used as the internal control, and the gene-specific mRNA expression was normalized against $\beta$-actin expression. The sequences of the primers used in these analyses are listed in Table I.

Statistical analysis. Data are presented as the means \pm SD. The data were compared using two-tailed unpaired Student's t-test (SPSS 13.0 for Windows). $\mathrm{P}<0.05$ was indicative of a statistically significant difference.

\section{Results}

Morphological features of osteoclasts derived from RAW264.7 cells. After RAW264.7 cells were plated in flasks and treated with RANKL for 7 days, they were stained with TRAP and counterstained with hematoxylin. The adherent osteoclasts displayed a ruffled membrane (Fig. 1A), pseudopodia and a multinuclei phenotype (Fig. 1B).

Expression of TRAP, CTR, integrin $\beta 3$ and RANK $m R N A$. To examine the effect of RANKL on the initial proliferation of osteoclast precursor cells, RAW264.7 cells were grown

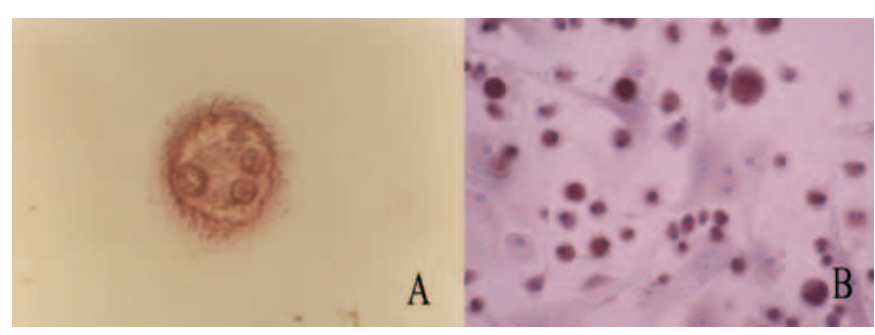

Figure 1. Morphological features of osteoclasts that were derived from RAW264.7 cells. (A) A large mature osteoclast was stained for TRAP and displayed a ruffled membrane. (B) Osteoclast was counterstained with hematoxylin.

in the presence of $50 \mathrm{ng} / \mathrm{ml}$ of RANKL for up to 7 days. RANKL-induced osteoclast precursor cells had increased TRAP and RANK expression and decreased CTR expression compared to the control cells not treated with RANKL (Fig. 2).

To investigate the effect of radiation on osteoclast precursor cells, RAW264.7 cells were exposed to 2-Gy $\gamma$-rays and maintained without RANKL for up to 7 days. These osteoclast precursor cells had upregulated integrin $\beta 3$ and RANK expression and downregulated CTR expression compared to the control cells (Fig. 2).

To evaluate the effect of radiation on RANKL-induced osteoclast differentiation, we compared an expression panel of osteoclast marker genes in RAW264.7 cells that were treated with RANKL alone or in combination with radiation. The irradiation of RANKL-induced osteoclasts led to an increased expression of CTR and a decreased expression of RANK and TRAP compared to the non-irradiated RANKL-induced osteoclasts (Fig. 2).

\section{Discussion}

Bone metabolism is a dynamic and continuous remodeling process that is normally maintained in a tightly coupled balance between resorption of old or injured bone and the formation of new bone. This coordinated regulation of bone-forming cells (osteoblasts) and bone-resorbing cells (osteoclasts) is regulated by a complex network of cytokines, cell surface receptors and various signaling pathways (10). Osteoclasts are derived from hematopoietic progenitor cells of a monocyte/ macrophage lineage and multinucleated cells that degrade the mineralized bone matrix (11). Recent studies have identified activated osteoclasts as a pathological feature of osteopenia and osteoporosis (12). Osteoclast precursors synthesize DNA and proliferate. Therefore, osteoclast precursors are more vulnerable to radiation injury than osteoclasts. Little attention has been given to evaluating the effects of radiation on osteoclast precursor function.

TRAP, a metallophosphatase that is highly expressed in osteoclasts, is secreted into the resorption lacuna and is associated with the resorbing matrix (13-16). TRAP expression is dramatically upregulated during osteoclast differentiation. Hence, TRAP activity is commonly used as a histochemical marker of osteoclasts (17). When activated by proteolytic processing, TR AP exhibits protein phosphatase activity toward several bone matrix proteins, including osteopontin $(15,16)$. In accordance with previous reports (18), our results show that RANKL-induced RAW264.7 cells had increased TRAP 
A

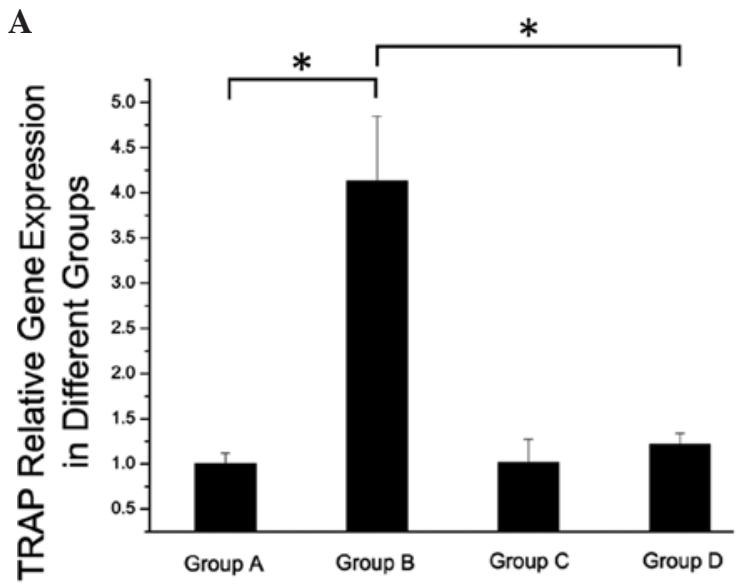

C

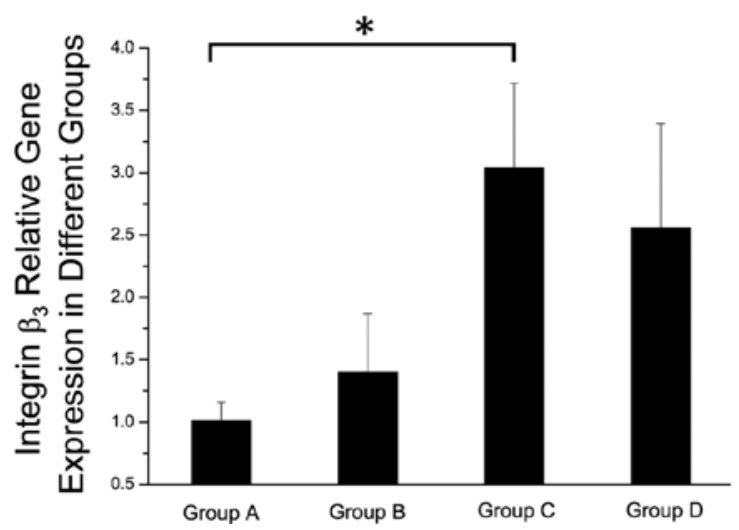

B

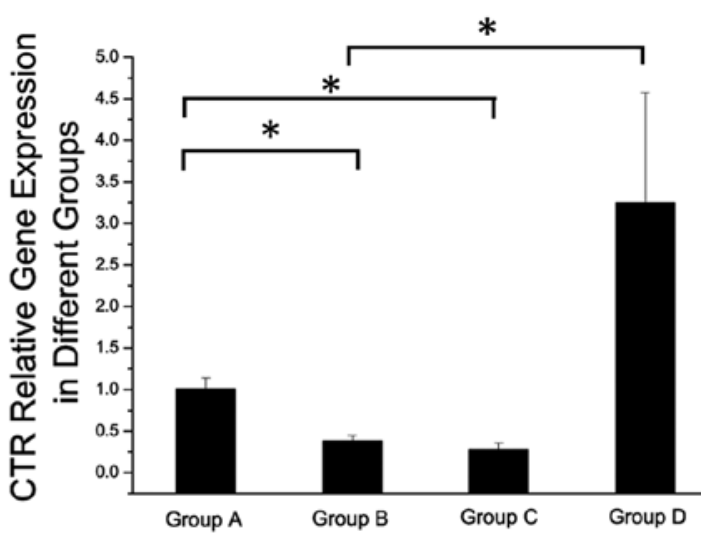

D

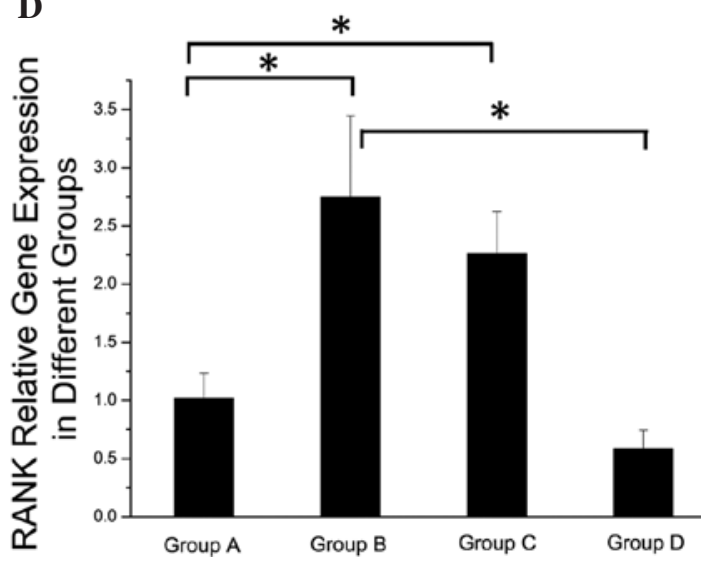

Figure 2. Relative expression of TRAP, CTR, integrin $\beta 3$ and RANK ( $\left.{ }^{*}<<0.05\right)$. The expression profiles of (A) TRAP, (B) CTR, (C) integrin $\beta 3$ and (D) RANK were determined using the $2^{-\Delta \Delta C t}$ method.

expression (group B). We demonstrated that the expression of TRAP was not significantly different between groups A and $\mathrm{C}$, suggesting that radiation may have little impact on TRAP expression in osteoclast precursors. We initially hypothesized that TRAP expression in irradiated mature osteoclasts may be higher compared to non-irradiated counterparts according to skeletal complications in patients receiving radiotherapy. Notably, group D, which comprised RANKL-induced RAW264.7 cells that were irradiated with $2-\mathrm{Gy}{ }^{137} \mathrm{Cs} \gamma$-rays, showed lower levels of TRAP than group B, in which the cells were cultivated in the presence of $50 \mathrm{ng} / \mathrm{ml}$ of RANKL for osteoclast formation. These results indicate that radiation may have a negative effect on TRAP expression, although the underlying mechanism remains unknown.

As part of bone remodeling, osteoclasts bind to the bone matrix, form an actin ring-mediated sealing zone, secrete enzymes and acid to degrade the bone and then migrate to a new site. Each of these functions is regulated in part by integrins that are located on the membrane surface of the osteoclast and interact with neighboring cells and the extracellular matrix (19). The predominant integrin in osteoclasts is $\alpha v \beta 3$. Antibody inhibition of $\alpha v \beta 3$ inhibits osteoclast attachment to the bone matrix and osteoclast-mediated bone resorption (20). The $\beta 3$ subunit, which is a component of $\alpha \operatorname{II} \beta 3$ and $\alpha v \beta 3$ integrins, plays an important role during early fracture healing (21). Our findings indicate that irradiated RAW264.7 cells expressed significantly higher levels of integrin $\beta 3$ than the control group. However, the expression levels of integrin $\beta 3$ between groups B and D showed no significant differences. These results suggest that irradiation promotes the activity of osteoclast precursor cells, but not that of osteoclasts.

In the bone, CTR is a specific marker of osteoclasts (22-25), particularly osteoclast differentiation (26), and osteoclasts are normally associated with osteolysis. The binding of calcitonin to its receptor is known to dampen osteoclast activation (27). We found that cells in the RANKL-induced group and the irradiated group expressed lower levels of CTR than those in the control group, suggesting that mature osteoclasts express lower levels of CTR than osteoclast precursors. However, cells in the group receiving RANKL in combination with radiation treatment expressed higher levels of CTR compared to those in the control group. Our results suggest that radiation exposure may increase the activity of osteoclast precursors, but may damage the resorption ability of osteoclasts.

RANK expression on hematopoietic precursor cells is required in the murine model for osteoclast differentiation and activation, the resorption of bone and the regulation of calcium homeostasis by calcitropic hormones $(28,29)$. Our results showed that cells in the RANKL-induced group (group B) and the irradiated group (group C) expressed higher levels of RANK. The RANK mRNA expression did not significantly differ between groups $\mathrm{C}$ and $\mathrm{D}$. The irradiation 
of RANKL-induced osteoclasts (group D) led to a decreased RANK expression compared to the cells in group B. These results suggest that radiation exposure may promote RANK expression in osteoclast precursors, but not in osteoclasts.

In conclusion, our experiments revealed that RAW264.7 cells differentiated into functional osteoclasts in the presence of RANKL. Radiation damage may promote the activities of osteoclast precursors, but it decreases those of osteoclasts. We inferred that radiation impairs the function of osteoclasts and stimulates the differentiation of osteoclast precursors. Therefore, irradiated osteoclast precursors may play a significant role in bone damage and may mediate skeletal complications in patients receiving radiotherapy.

\section{Acknowledgements}

This study was supported by grants from the National Nature Science Foundation of China (no. 30970867) (http://www.nsfc. gov.cn).

\section{References}

1. Banfi A, Bianchi G, Galotto M, Cancedda R and Quarto R: Bone marrow stromal damage after chemo/radiotherapy: occurrence, consequences and possibilities of treatment. Leuk Lymphoma 42: 863-870, 2001.

2. Baxter NN, Habermann EB, Tepper JE, Durham SB and Virnig BA: Risk of pelvic fractures in older women following pelvic irradiation. JAMA 294: 2587-2593, 2005.

3. Darzy KH and Shalet SM: Hypopituitarism after cranial irradiation. J Endocrinol Invest 28: 78-87, 2005.

4. Langlands AO, Souter WA, Samuel E and Redpath AT: Radiation osteitis following irradiation for breast cancer. Clin Radiol 28: 93-96, 1977.

5. Cuetara BL, Crotti TN, O'Donoghue AJ and McHugh KP: Cloning and characterization of osteoclast precursors from the RAW264.7 celline. In Vitro Cell Dev Biol Anim 42: 182-188, 2006.

6. Ito M, Matsuka N, Izuka M, et al: Characterization of inorganic phosphate transport in osteoclast-like cells. Am J Physiol Cell Physiol 288: C921-C931, 2005.

7. Hsu H, Lacey DL, Dunstan CR, et al: Tumor necrosis factor receptor family member RANK mediates osteoclast differentiation and activation induced by osteoprotegerin ligand. Proc Natl Acad Sci USA 96: 3540-3545, 1999.

8. Burgess TL, Qian Y, Kaufman S, et al: The ligand for osteoprotegerin (OPGL) directly activates mature osteoclasts. J Cell Biol 145: 527-538, 1999.

9. Makihira S, Mine Y, Kosaka E and Nikawa H: Titanium surface roughness accelerates RANKL-dependent differentiation in the osteoclast precursor cell line, RAW264.7. Dent Mater J 26: 739-745, 2007.

10. Haynes DR, Crotti TN and Zreiqat H: Regulation of osteoclast activity in peri-implant tissues. Biomaterials 25: 4877-4885, 2004.
11. Asagiri $\mathrm{M}$ and Takayanagi $\mathrm{H}$ : The molecular understanding of osteoclast differentiation. Bone 40: 251-264, 2007.

12. Willey JS, Livingston EW, Robbins ME, Bourland JD, Tirado-Lee L, Smith-Sielicki H and Bateman TA: Risedronate prevents early radiation-induced osteoporosis in mice at multiple skeletal locations. Bone 46: 101-111, 2010.

13. Hollberg K, Nordahl J, Hultenby K, Mengarelli-Widholm S, Andersson G and Reinholt FP: Polarization and secretion of cathepsin K precede tartrate-resistant acid phosphatase secretion to the ruffled border area during the activation of matrixresorbing clasts. J Bone Miner Metab 23: 441-449, 2005.

14. Kirstein B, Chambers TJ and Fuller K: Secretion of tartrateresistant acid phosphatase by osteoclasts correlates with resorptive behavior. J Cell Biochem 98: 1085-1094, 2006.

15. Andersson G, Ek-Rylander B, Hollberg K, et al: TRACP as an osteopontin phosphatase. J Bone Miner Res 18: 1912-1915, 2003.

16. Suter A, Everts V, Boyde A, et al: Overlapping functions of lysosomal acid phosphatase (LAP) and tartrate-resistant acid phosphatase (Acp5) revealed by doubly deficient mice. Development 128: 4899-4910, 2001.

17. Walsh NC, Cahill M, Carninci P, et al: Multiple tissue-specific promoters control expression of the murine tartrate-resistant acid phosphatase gene. Gene 307: 111-123, 2003.

18. Battaglino R, Kim D, Fu J, Vaage B, Fu XY and Stashenko P: c-myc is required for osteoclast differentiation. J Bone Miner Res 17: 763-773,2002

19. Teitelbaum SL and Ross FP: Genetic regulation of osteoclast development and function. Nat Rev Genet 4: 638-649, 2003.

20. Ross FP, Chappel J, Alvarez JI, et al: Interactions between the bone matrix proteins osteopontin and bone sialoprotein and the osteoclast integrin alpha v beta 3 potentiate bone resorption. J Biol Chem 268: 9901-9907, 1993.

21. Hu D, Lu C, Sapozhnikova A, Barnett M, Sparrey C, Miclau T and Marcucio RS: The absence of beta-3 integrin accelerates early skeletal repair. J Orthop Res 28: 32-37, 2010.

22. Nicholson GC, Moseley JM, Sexton PM, Mendelsohn FA and Martin TJ: Abundant calcitonin receptors in isolated rat osteoclasts. Biochemical and autoradiographic characterization. J Clin Invest 78: 355-360, 1986.

23. Zaidi M, Pazianas M, Shankar VS, et al: Osteoclast function and its control. Exp Physiol 78: 721-739, 1993.

24. Quinn JM, Morfis M, Lam MH, et al: Calcitonin receptor antibodies in the identification of osteoclasts. Bone 25: 1-8, 1999

25. Cornish J, Callon KE, Bava U, Kamona SA, Cooper GJ and Reid IR: Effects of calcitonin, amylin, and calcitonin gene-related peptide on osteoclast development. Bone 29: 162-168, 2001.

26. Lee SK, Goldring SR and Lorenzo JA: Expression of the calcitonin receptor in bone marrow cell cultures and in bone: a specific marker of the differentiated osteoclast that is regulated by calcitonin. Endocrinology 136: 4572-4581, 1995.

27. Boyle WJ, Simonet WS and Lacey DL: Osteoclast differentiation and activation. Nature 423: 337-342, 2003.

28. Li J, Sarosi I, Yan XQ, et al: RANK is the intrinsic hematopoietic cell surface receptor that controls osteoclastogenesis and regulation of bone mass and calcium metabolism. Proc Natl Acad Sci USA 97: 1566-1571, 2000.

29. Dougall WC, Glaccum M, Charrier K, et al: RANK is essential for osteoclast and lymph node development. Genes Dev 13: 2412-2424, 1999. 